\title{
Article \\ HeGRI: A Novel Index of Serum Hepcidin Suppression in Relation to the Degree of Renal Dysfunction among $\beta$-Thalassemia Major Patients
}

\author{
Burhan A. Zaman ${ }^{1, *(D)}$, Suzan O. Rasool ${ }^{2}$, Nashwan M. R. Ibrahim ${ }^{3}$ and Deldar M. Abdulah ${ }^{4}(\mathbb{D}$ \\ 1 Department of Basic Sciences, College of Pharmacy, University of Duhok, \\ Duhok City 42001, Kurdistan Region, Iraq \\ 2 Department of Clinical Pharmacy, College of Pharmacy, University of Duhok, \\ Duhok City 42001, Kurdistan Region, Iraq; suzan.rasool@uod.ac \\ 3 Department of Surgery, College of Medicine, University of Duhok, Duhok City 42001, Kurdistan Region, Iraq; \\ nashwan.ibrahim@uod.ac \\ 4 Community and Maternity Health Unit, College of Nursing, University of Duhok, \\ Duhok City 42001, Kurdistan Region, Iraq; deldarmorad@uod.ac \\ * Correspondence: burhan.zaman@uod.ac; Tel.: +964-7514044047; Fax: +964-7504383789
}

Citation: Zaman, B.A.; Rasool, S.O.; Ibrahim, N.M.R.; Abdulah, D.M. HeGRI: A Novel Index of Serum Hepcidin Suppression in Relation to the Degree of Renal Dysfunction among $\beta$-Thalassemia Major Patients Thalass. Rep. 2022, 12, 2-11. https:// doi.org/10.3390/thalassrep12010002

Academic Editor: Aurelio Maggio

Received: 29 August 2021

Accepted: 3 December 2021

Published: 15 December 2021

Publisher's Note: MDPI stays neutral with regard to jurisdictional claims in published maps and institutional affiliations.

Copyright: (c) 2021 by the authors. Licensee MDPI, Basel, Switzerland. This article is an open access article distributed under the terms and conditions of the Creative Commons Attribution (CC BY) license (https:// creativecommons.org/licenses/by/ $4.0 /)$.

\begin{abstract}
Background: The progressive renal function inadequacy results in altered hepcidin metabolism due to a shifting of its renal elimination, which consequently affects enteric iron absorption and iron stores' availability. This study aimed to investigate and correlate renal function, iron status, and hepcidin in patients with $\beta$-thalassemia major through a novel index. Methods: In this 1:1 case-control study, serum hepcidin, serum ferritin, iron study, hematological and renal function parameters were compared between $60 \beta$-thalassemia major patients with iron overload and 61 healthy individuals (2-30 years old). Results: The concentrations of serum hepcidin (21.898 vs. $9.941 \mathrm{ng} / \mathrm{mL} ; p<0.001)$ and eGFR (179.71 vs. 132.95; $p<0.001)$ were significantly higher in $\beta$-thalassemia major patients compared to the controls. The serum hepcidin levels decreased with increasing levels of total iron-binding capacity (TIBC; $\beta=-0.442 ; p=0.024)$, transferrin saturation $(\beta=-0.343 ; p=0.023)$, serum creatinine $(\beta=-0.625 ; p=0.0030)$, and eGFR $(\beta=-0.496 ; p=0.011)$. The mean hepcidin/ferritin ratio was significantly lower in the $\beta$-thalassemia major cases $(0.0069$ vs. 0.3970; $p<0.001)$. The novel hepcidin/eGFR ratio index (HeGRI) was significantly higher in the patient group compared to controls $(0.12$ vs. $0.09 ; p=0.031)$, respectively. Conclusions: These results suggest that HeGRI could be a potential index of the appropriateness of serum hepcidin suppression associated with the degree of renal dysfunction among $\beta$-thalassemia major patients.
\end{abstract}

Keywords: hepcidin; eGFR; renal dysfunction; iron overload; $\beta$-thalassemia major

\section{Introduction}

Thalassemia is a common single-gene disease with two main classical types, $\alpha$ - and $\beta$-thalassemia [1]. $\beta$-thalassemia major is a genetic hemolytic anemia. A lack of the $\beta$-chain synthesis of hemoglobin in $\beta$-thalassemia major results in ineffective erythropoiesis and hemolysis; accordingly, it leads to marked anemia. Patients with $\beta$-thalassemia major have a high level of erythropoietin resulting in considerable erythroid hyperplasia. The excessive dietary iron absorption and repetitive blood transfusion results in iron accumulation and severe iron overload [2].

Excess tissue iron load is responsible for a considerable amount of morbidity and mortality, similarly seen in $\beta$-thalassemia major, Diamond-Blackfan anemia, sickle cell anemia, pyruvate kinase insufficiency, and congenital dyserythropoietic anemia [3].

Hepcidin, a liver-derived peptide hormone, plays a key role in regulating the homeostasis of systemic iron. Its unbalanced output contributes to the pathogenesis of iron 
disorders [4]. Hepcidin is related to the intracellular iron exporter ferroportin and causes its internalization and degradation [5].

Iron reflexively regulates hepcidin levels to regulate plasma iron levels. Excess iron stimulates hepcidin production, which results in the blockage of iron absorption in the intestines, on the other hand hepcidin production is suppressed in iron deficiency anemia. The feedback loop between iron and hepcidin should ensure the proper physiological concentration of iron in plasma $[4,6]$.

Hepcidin levels should increase in $\beta$-thalassemia major patients due to the iron overload, but a paradoxically low hepcidin level is observed in these patients because of ineffective erythropoiesis [2].

Many studies of hepcidin in humans used a urinary assay, but it does not reflect the serum hepcidin levels in patients with chronic kidney diseases. In other words, these studies have measured the levels of prohepcidin, a peptide precursor of hepcidin [7]. These studies do not reflect the clear link between prohepcidin, hepcidin, and serum iron concentrations $[8,9]$.

The serum hepcidin could be measured by mass spectrometry; in addition, it detects the correlation between serum hepcidin and ferritin levels in patients with chronic kidney diseases. This technique is a semi-quantitative and requires spectrometric equipment, which is not widely available [10].

While hepcidin is excreted from the body via urine, progressive renal insufficiency results in altering hepcidin metabolism [11], subsequently affecting enteric iron absorption and availability [10].

In this study, we present the first quantitative 1:1 age- and gender-matched casecontrol comparisons of serum hepcidin in $\beta$-thalassemia major patients with iron overload, to identify the degree of renal dysfunction through a novel index. The index is serumhepcidin-to-estimated-glomerular-filtration-rate (eGFR) ratio (called HeGRI; in which $\mathrm{H}$ stands for hepcidin, eG for eGFR, $\mathrm{R}$ for ratio, and I for index). This index could be a potential index of serum hepcidin suppression in relation to the degree of tubular dysfunction and glomerular hyperfiltration.

\section{Materials and Methods}

\subsection{Study Design, Sampling, and Patients}

This matched case-control 1:1 study included 121 participants, aged ranging from 2 to 30 years (66 females and 55 males), who were allocated based on the following criteria. The first (case) group had $60 \beta$-thalassemia major patients with iron overload. The second (control) group comprised 61 healthy individuals matched with the cases in their age and sex. The data were collected from 10 August 2019 to 10 October 2019.

\subsection{Inclusion and Exclusion Criteria}

Patients were included in the study if they were 2 to 30 years of age, both male and female, and irrespective of any socio-demographic differences. The control subjects were excluded if diagnosed with thalassemia of any type with or without iron overload of any substantial cause.

\subsection{Diagnostic and Measurement Criteria}

The following information were recorded in a predesigned questionnaire, including age, gender, the relation of parents, type of thalassemia in parents, number of transfusions per month, and the first transfusion time for each patient. The study groups were recruited based on the following criteria-case group: $\beta$-thalassemia major patients were included with iron overload based on a serum ferritin $>400 \mathrm{ng} / \mathrm{mL}$; control group: healthy individuals without thalassemia and with normal iron status were included based on a serum ferritin within a normal range of $7-140 \mathrm{ng} / \mathrm{mL}$ (for children 6 months-15 years), 10-120 ng/mL (for adult females), and 20-250 ng/mL (for adult males). 


\subsection{Laboratory Measurement}

The venous blood samples were taken from the appropriate forearm vein, $7 \mathrm{~mL}$ from each patient immediately before blood transfusion. In this regard, $2 \mathrm{~mL}$ of blood was placed into an EDTA tube. The blood was sent to the laboratory for complete blood count assessment. The complete blood count test was performed using the hematology auto-analyzer (Swelab Coulter Counter- Boule International, Stockholm, Sweden). The remaining $5 \mathrm{~mL}$ of blood was put into a plain gel tube to obtain serum, in which the serum of each participant was divided into three separate capped collecting tubes: one for iron studies (serum ferritin, serum iron, and TIBC), one for renal function tests (serum creatinine and serum urea), and the last one for serum hepcidin analysis.

We used a creatinine reagent set to determine in vitro assessment of serum creatinine using the automated chemistry analyzer Biolis 24i (Boeki Medisys Inc., Tokyo, Japan). This method assesses the serum creatinine based on a modification of the Jaffe reaction procedure, incorporating a surfactant and other ingredients to minimize protein and carbohydrate interference. In this method, serum creatinine reacts with picric acid in basic conditions and forms a color complex (yellow-orange). The complex absorbs at $510 \mathrm{~nm}$ wavelengths. The color formation is proportional to the creatinine concentration in the sample.

Serum urea nitrogen was identified using an in vitro BUN reagent set for quantitative assessment of serum urea nitrogen (Boeki Medisys Inc., Tokyo, Japan) automated chemistry analyzer Biolis 24i analyzer). This procedure is performed by using a modified Talke and Schubert method. Urease hydrolyses urea and produces ammonia and carbon dioxide. The produced ammonia reacts with $\alpha$-ketoglutarate using NADH and leads to glutamate. An equimolar quantity of NADH undergoes oxidation during the reaction and results in an absorbance decrease. This absorption is directly proportional to the urea nitrogen concentration.

For calculation of eGFR in $\mathrm{mL} / \mathrm{min} / 1.73 \mathrm{~m}^{2}$, we used two different equations: creatininebased "Bedside Schwartz" equation, which is used for age range 1 to 18 years old, and expressed as [12]:

$$
\mathrm{eGFR}=0.413 \times(\text { height }(\text { in } \mathrm{cm}) / \text { serum creatinine })
$$

and "CKD-EPI" equation**, which is used for adults greater than 18 years old, expressed as [13]:

$$
\begin{aligned}
\mathrm{eGFR}= & 141 \times \min (\text { serum creatinine } / \mathrm{k}, 1) \mathrm{a} \times \max (\text { serum creatinine } / \mathrm{k}, 1)- \\
& 1.209 \times 0.993 \text { Age } \times 1.018(\text { if female }) \times 1.159(\text { if black })
\end{aligned}
$$

** In CKD-EPI (chronic kidney disease epidemiology collaboration) equation: $\mathrm{k}$ is 0.7 for females and 0.9 for males, $\mathrm{a}$ is -0.329 for females and -0.411 for males, min indicates the minimum of $\mathrm{S}$. creatinine/k or 1 and max indicate the maximum of $\mathrm{S}$. creatinine/k or 1 .

Serum hepcidin was measured using a DRG hepcidin-25 (bioactive) high sensitivity ELISA kit, with a catalogue reference number of ELA-5782, 2019 hepcidin-25 bioactive high sensitivity ELISA, DRG Instruments GmbH, Germany and DRG international, Inc., USA. It is a highly sensitive enzyme immunoassay for the quantitative in vitro diagnostic identification of plasma or serum hepcidin-25. The reference values were between 1.49 and $41.46 \mathrm{ng} / \mathrm{mL}$.

Serum ferritin was determined by an automated quantitative enzyme-linked fluorescent assay technique, using the VIDAS ferritin kit to detect human plasma or serum ferritin, VIDAS hormonal analyzer, (BioMérieux SA Company, Marcy-LEtoile, France).

Serum iron and unsaturated iron-binding capacity (UIBC) were measured by an enzymatic colorimetric method, called the FerroZine method (Cobas Integra Iron Gen.2 and UIBC kits, for the quantitative detection of human plasma or serum iron, and UIBC via the COBAS INTEGRA 400/800 system, (Roche Diagnostics GmbH, Mannheim, Germany). Total iron-binding capacity (TIBC) was calculated as serum iron + UIBC $=$ TIBC. Moreover, 
transferrin saturation $(\%)$ was calculated by transferrin saturation $(\%)=100 \times$ serum iron/TIBC [14].

C-reactive protein (CRP) was detected by the particle-enhanced turbidimetric immunoassay (PETIA) method by using Cobas Integra CRP latex (CRPLX) for the quantitative immunological measurement of CRP in human plasma and serum on the COBAS INTEGRA 400/800 system, Roche Diagnostics GmbH (Germany). The assay principle is based on the agglutination of human CRP with latex particles coated with monoclonal anti-CRP antibodies. The resultant precipitate is identified turbidimetrically at a wavelength of $552 \mathrm{~nm}$.

\subsection{Statistical Analysis}

The general characteristics of patients were presented as mean and standard deviation for normal variables (age, renal, and hematological), and median and interquartile range for non-normal variables (transfusion start period, hepcidin, CRP, and transferrin saturation). The homogeneity of the study groups was examined in independent $t$-tests or Pearson's Chi-square tests. The comparison of hematological and renal function parameters between $\beta$-thalassemia major patients and their matched controls was examined with independent $t$-tests and Mann-Whitney U-tests. The comparison of hepcidin between $\beta$-thalassemia major patients and their matched controls was examined with Mann-Whitney U-tests. The correlation of serum hepcidin with renal function test and hematological parameters were examined in bivariate correlation adjusting for age, gender, and study groups. A $p$-value of $<0.05$ was considered a statistically significant difference and correlation. The statistical calculations were performed by Statistical Package for Social Sciences 25 (IBM SPSS Statistics for Windows, Version 25.0; Armonk, NY, USA, IBM Corp.).

\subsection{Ethical Considerations}

Ethical approval was obtained from the Duhok research ethics committee at the General Directorate of Health (reference number: 10092019-6; 10 September 2019). Confidentiality of all personal information about the patients in this study was upheld.

\section{Results}

Our study revealed that the subjects in both controls and cases were comparable in age (11.41 vs. 11.42$)$, gender (male: $45.9 \%$ vs. $45.0 \%)$, and relation of the parents $(45.9 \%$ vs. $53.3 \%)$. The majority of the mothers $(98.3 \%)$ and all the fathers of the cases were carrier for thalassemia. The patients on average received 1.47 (SD: 0.50) blood transfusions per a month. The average total number of transfusions in the cases were 88 . The median time of first blood transfusion at the beginning of diagnosis was 7.0 months old (interquartile range: 6.0 ); these data are not shown in the tables.

The study revealed that the patients had significantly higher levels of WBC, MCHC, iron, and serum ferritin and lower levels of RBC, hemoglobin, HCT, MCV, MCH, and TIBC compared to the subjects in the control group (Table 1).

Table 1. Comparison of hematological parameters and iron study between patients with $\beta$-thalassemia major and their matched controls.

\begin{tabular}{llll}
\hline Hematological Parameters & $\begin{array}{l}\text { Study Groups } \\
\text { Controls }(\boldsymbol{n = 6 1 )}\end{array}$ & Cases $(\boldsymbol{n = 6 0 )}$ & Case-Control Difference \\
\hline WBC $(\mathbf{1 0} \mathbf{9} / \mathbf{L})$ & $7.61(1.73)$ & $9.87(3.56)$ & $2.26(1.83)$ \\
\hline RBC $(\mathbf{1 0} \mathbf{1 2} / \mathrm{L})$ & $4.91(0.53)$ & $3.02(0.44)$ & $-1.89(-0.09)$ \\
\hline Hemoglobin $(\mathbf{g} / \mathrm{dL})$ & $13.53(1.87)$ & $8.32(1.20)$ & $-5.21(-0.67)$ \\
\hline HCT (\%) & $38.93(5.54)$ & $21.82(3.38)$ & $-17.11(-2.16)$ \\
\hline MCV (fl) & $83.45(5.46)$ & $71.96(3.98)$ & $-11.49(-1.48)$ \\
\hline
\end{tabular}


Table 1. Cont.

\begin{tabular}{|c|c|c|c|}
\hline Hematological Parameters & $\begin{array}{l}\text { Study Groups } \\
\text { Controls }(n=61)\end{array}$ & Cases $(n=60)$ & Case-Control Difference \\
\hline MCH (pg) & $28.78(1.03)$ & $27.51(1.03)$ & $-1.27(0.00)$ \\
\hline MCHC (g/dL) & $34.47(0.80)$ & $38.10(0.93)$ & $3.63(0.13)$ \\
\hline Iron $(\mu \mathrm{g} / \mathrm{dL})$ & $106.80(38.53)$ & $237.66(45.50)$ & \\
\hline Normal/f (\%) & $42(68.9)$ & $0(0.0)$ & $130.86(6.97)$ \\
\hline Abnormal & $19(31.1)$ & $60(100.0)$ & \\
\hline TIBC $(\mu \mathrm{g} / \mathrm{dL})$ & $429.85(40.08$ & $280.48(91.68)$ & \\
\hline Normal/f (\%) & $12(19.7)$ & $27(45.0)$ & $-149.37(51.60)$ \\
\hline Abnormal & $49(80.3)$ & $33(55.0)$ & \\
\hline Transferrin saturation (\%) & $26.52(14.76)$ & $85.93(38.42)$ & $59.41(23.66)$ \\
\hline Serum ferritin $(\mathrm{ng} / \mathrm{mL})$ & $27.96(17.29)$ & $3435.53(1968.83)$ & \\
\hline Normal/f (\%) & $45(73.8)$ & $0(0.0)$ & 3407.57 (1951.54) \\
\hline Abnormal & $16(26.2)$ & $60(100.0)$ & \\
\hline
\end{tabular}

Independent $\mathrm{t}$-test was performed for statistical analyses except Man-Whitney U-test for transferrin saturation. The values are represented as mean (standard deviation) for all variables except transferrin saturation which is represented as median (interquartile range). $p<0.001$ for all.

The patients with $\beta$-thalassemia major had significantly higher concentrations of hepcidin ( 21.898 vs. $9.941 ; p<0.001)$ and CRP $(0.54$ vs. $0.11 ; p<0.001)$ compared to the subjects in the control group, whereas the levels of serum creatinine were significantly lower in the cases $(0.32$ vs. $0.44 ; p<0.001)$ compared to the subjects in the control group. The $\beta$-thalassemia major cases also had higher levels of eGFR compared to the controls (179.71 vs. 132.95; $p<0.001)$, as presented in Table 2 and Figure 1a.

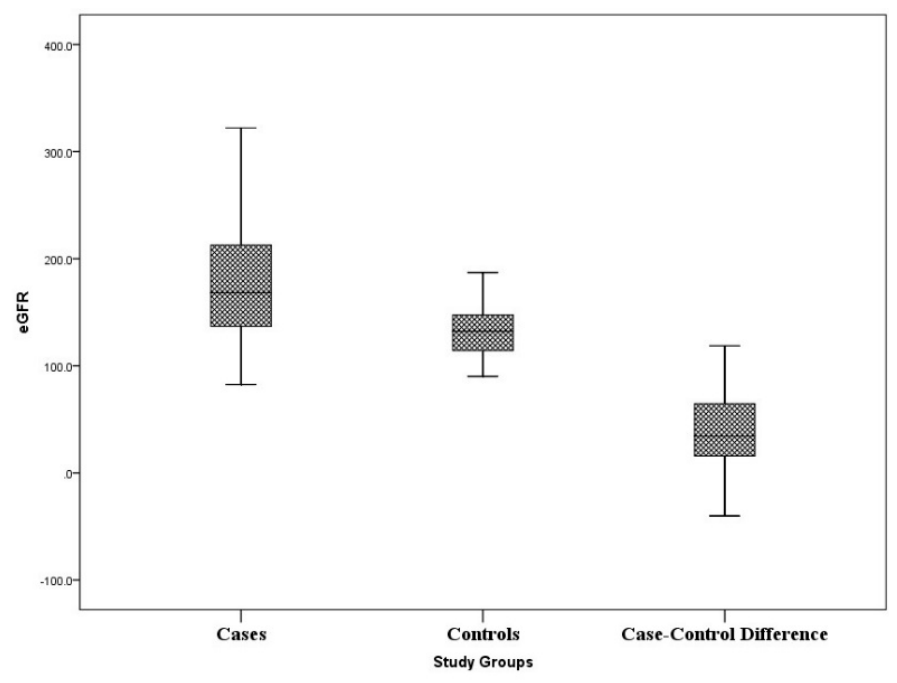

(a)

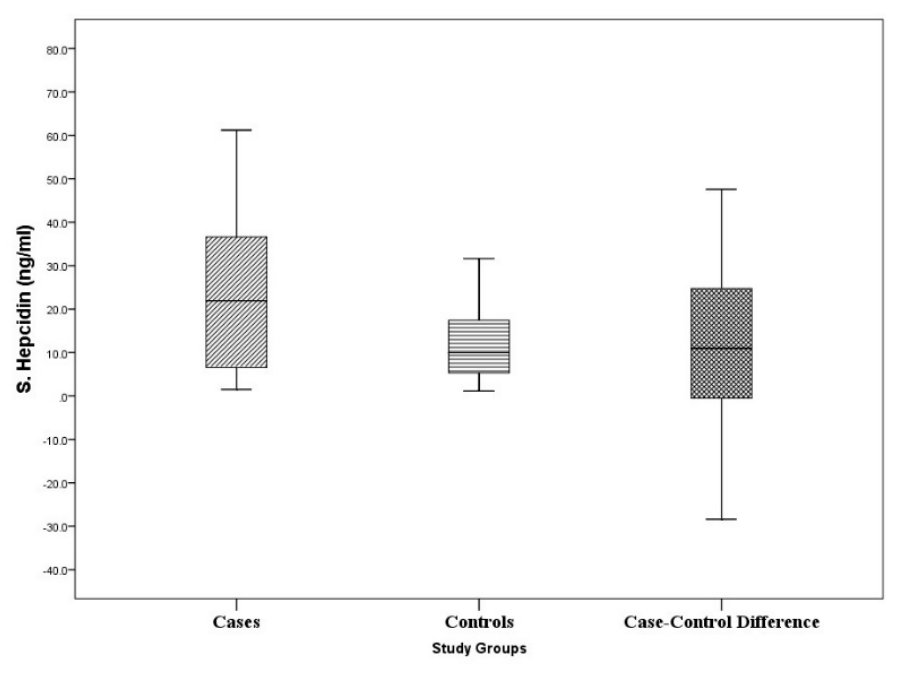

(b)

Figure 1. Comparison of (a) eGFR and (b) serum hepcidin between patients with $\beta$-thalassemia major and their matched controls. 
Table 2. Comparison of hepcidin, CRP and renal function parameters between patients with $\beta$-thalassemia major and their matched controls.

\begin{tabular}{lllll}
\hline Parameters & Controls $(\boldsymbol{n}=\mathbf{6 1})$ & Cases $(\boldsymbol{n}=\mathbf{6 0})$ & Case-Control Difference & $p$-Value (Two-Tailed) \\
\hline Hepcidin & $9.941(12.271)$ & $21.898(30.087)$ & $11.96(17.82)$ & $<0.001^{*}$ \\
\hline CRP & $0.11(0.62)$ & $0.54(2.04)$ & $0.43(1.42)$ & $<0.001^{*}$ \\
\hline Blood urea (mg/dL) & & & $2.19(-1.06)$ & $0.060^{* *}$ \\
$\begin{array}{l}\text { Normal } \\
\text { Abnormal }\end{array}$ & $22(36.1)$ & $8(13.3)$ & & 0.004 \\
\hline Serum creatinine & $39(63.9)$ & $52(86.7)$ & $-0.12(-0.04)$ & $<0.001^{* *}$ \\
(mg/dL) & & & 0.003 \\
Normal & $36(59.0)$ & $19(31.7)$ & $41(68.3)$ & $<0.001^{* *}$ \\
Abnormal & $25(41.0)$ & $179.71(55.53)$ & $46.76(31.22)$ & $0.027^{* *}$ \\
\hline eGFR & $132.95(24.31)$ & $162.08(26.05)$ & $25.34(10.02)$ & $<0.001^{* *}$ \\
Adult (>18 years) & $136.74(16.03)$ & $182.83(58.86)$ & $50.54(33.33)$ & \\
Pediatric (1-18 years) & $132.29(25.53)$ & & \\
\hline
\end{tabular}

* Mann-Whitney U-test and ${ }^{* *}$ independent $\mathrm{t}$-tests were performed for statistical analyses. The values are represented as median (interquartile range) * and mean (standard deviation) **.

Furthermore, the study revealed that the serum hepcidin of the cases were more broadly dispersed compared to their compatriots in the control group, as in Figure $1 \mathrm{~b}$.

In terms of a linear regression, the correlations between serum hepcidin and the iron study, hematological parameters, CRP, eGFR, blood urea, and serum creatinine were examined. The analysis showed that levels of serum hepcidin were increased with decreased levels of TIBC $(\beta=-0.442 ; p=0.024)$, transferrin saturation $(\beta=-0.343 ; p=0.023)$, creatinine $(\beta=-0.625 ; p=0.003)$, and eGFR $(\beta=-0.496 ; p=0.011)$, as shown in Table 3 .

Table 3. Role of eGFR, renal function parameters, and iron status on serum hepcidin level in patients with $\beta$-thalassemia major.

\begin{tabular}{|c|c|c|c|c|c|}
\hline \multirow{3}{*}{$\begin{array}{l}\text { Controlling } \\
\text { Factors }(n=60)\end{array}$} & \multicolumn{5}{|c|}{ Dependent Variable: Serum Hepcidin (ng/mL) } \\
\hline & \multirow{2}{*}{$\begin{array}{l}\text { Standardized } \\
\text { Coefficients } \\
\text { Beta }\end{array}$} & \multirow{2}{*}{$\mathbf{T}$} & \multirow{2}{*}{$p$-Value } & \multicolumn{2}{|c|}{$95.0 \%$ Confidence Interval for B } \\
\hline & & & & Lower Bound & Upper Bound \\
\hline Iron $(\mu \mathrm{g} / \mathrm{dL})$ & -0.101 & -0.596 & 0.554 & -0.174 & 0.095 \\
\hline TIBC $(\mu \mathrm{g} / \mathrm{dL})$ & -0.442 & -2.346 & 0.024 & -0.159 & -0.012 \\
\hline TS (\%) & -0.343 & -2.353 & 0.023 & -0.481 & -0.037 \\
\hline Serum ferritin $(\mathrm{ng} / \mathrm{mL})$ & 0.185 & 1.474 & 0.148 & -0.001 & 0.003 \\
\hline Urea $(\mathrm{mg} / \mathrm{dL})$ & 0.190 & 1.522 & 0.135 & -0.174 & 1.241 \\
\hline Creatinine $(\mathrm{mg} / \mathrm{dL})$ & -0.625 & -3.185 & 0.003 & -141.672 & -31.764 \\
\hline CRP (mg/L) & 0.039 & 0.281 & 0.780 & -3.068 & 4.060 \\
\hline eGFR & -0.496 & -2.657 & 0.011 & -0.261 & -0.036 \\
\hline
\end{tabular}

The linear regression model was performed for statistical analysis. The blue bold number show the controlling factors.

The study showed that the patients had significantly higher hepcidin/eGFR ratio $(0.12$ vs. $0.09 ; p=0.031$, while the mean hepcidin/ferritin ratio was significantly lower in the cases compared to the controls ( 0.0069 vs. 0.3970; $p<0.001)$; see Table 4 and Figure 2. 
Table 4. Comparison of hepcidin, hepcidin/ferritin and hepcidin/eGFR ratio between controls and cases.

\begin{tabular}{lllll}
\hline \multicolumn{1}{c}{ Parameters } & \multicolumn{1}{c}{ Controls $(\boldsymbol{n = 6 1 )}$} & \multicolumn{1}{c}{ Cases $(\boldsymbol{n = 6 0 )}$} & \multicolumn{1}{c}{$\begin{array}{c}\text { Case-Control } \\
\text { Difference }\end{array}$} & $p$-Value (Two-Tailed) \\
\hline Hepcidin/eGFR total & $0.09(0.11)$ & $0.12(0.15)$ & $0.03(0.04)$ & 0.031 \\
Hepcidin/eGFR child & $0.08(0.11)$ & $0.12(0.16)$ & $-0.04(0.05)$ & 0.023 \\
Hepcidin/eGFR adult & $0.06(0.08)$ & $0.12(0.13)$ & $-0.06(0.05)$ & 0.001 \\
\hline Hepcidin & $9.941(12.271)$ & $21.898(30.087)$ & $11.96(17.82)$ & $<0.001 *$ \\
Hepcidin/ferritin ratio & & & & $<0.001 *$ \\
Min-max & $0.088-3.826$ & $0.000-0.046$ & -0.3901 & \\
Mean (SD) & $0.3970(0.1994)$ & $0.0069(0.0047)$ & & \\
\hline
\end{tabular}

* Mann-Whitney U-test and ** independent t-tests were performed for statistical analyses. The values are represented as median (interquartile range)* and mean (standard deviation) **.

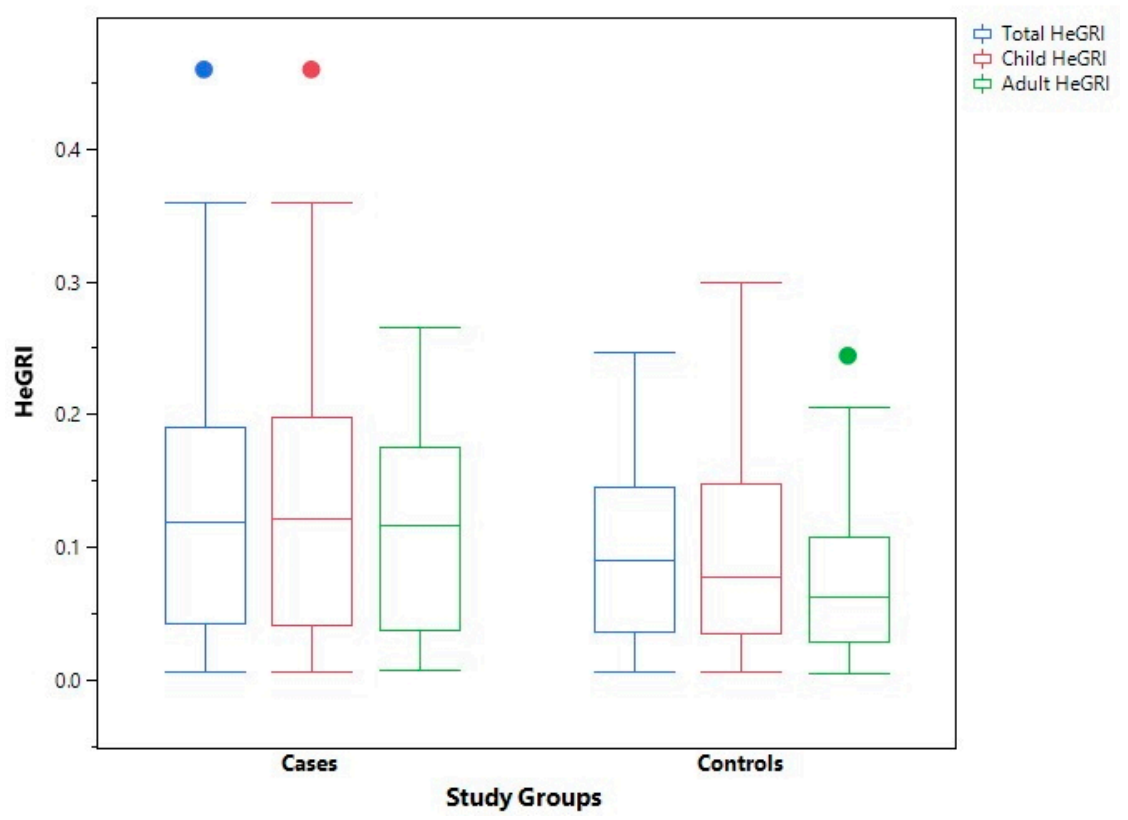

Figure 2. Comparisons of HeGRI indicators between cases and controls.

\section{Discussion}

Hepcidin is homeostatically regulated by iron and erythropoietic activity. However, similar patterns are involved in the dysregulation of hepcidin in thalassemia [15]. Iron overload and inflammation increase hepcidin synthesis, whereas anemia and hypoxia suppress hepcidin expression [2]. In $\beta$-thalassemia major, blood transfusion is a predominant responsible factor for iron overload rather than dietary iron absorption [16]. Iron overload should lead to increasing hepcidin levels in these patients; however, a paradoxical decrease in hepcidin is observed in thalassemic patients, caused by erythropoietin [2].

This study showed a significantly negative linear correlation of serum TIBC with serum hepcidin in which with decreasing serum hepcidin levels, there is an increase in the levels of plasma TIBC. Our findings are in agreement with a report by Gardenghi and Ramos [17] in which a significant negative linear correlation of serum TIBC with serum hepcidin emphasizes the role of hepcidin in regulating iron metabolism [17].

Hepcidin levels in $\beta$-thalassemia major are controlled by the suppressive effects of erythropoiesis and stimulatory effects of iron overload $[18,19]$. In this study, the patients with $\beta$-thalassemia major had significantly higher concentrations of hepcidin compared to their matched controls $(21.898$ vs. 9.941; $p<0.001)$. Low hepcidin levels, in turn, increase iron absorption. Therefore, estimating serum hepcidin levels could be useful for the management of iron overload in patients with $\beta$-thalassemia major $[20,21]$. 
While the median serum hepcidin $(21.898 \mathrm{ng} / \mathrm{mL})$ in our study was within normal ranges, it is considered to be highly suppressed compared to the very high median serum ferritin levels (3435.53 ng/mL).

It is generally accepted that hepcidin plays a key role in inflammation-related anemia [22]. Increased inflammation in cases such as $\beta$-Thalassemia major and chronic kidney disease can lead to higher serum hepcidin levels, further contributing to limit iron availability during erythropoiesis [10]. Progressive renal insufficiency results in altered hepcidin metabolism due to renal elimination and regulation of inflammation, subsequently affecting enteric iron absorption and the availability of iron stores [14]. In this study, using a novel assay, we presented the first quantitative measurements of bioactive serum hepcidin to measure renal function in patients with $\beta$-thalassemia major. The confirmation of pathological suppression of the iron regulatory hormone hepcidin in patients with $\beta$-thalassemia simplified these counterintuitive findings $[23,24]$.

The current study showed a statistically significant higher blood urea and eGFR in the patient group compared with the control group. In addition, the patients were more likely to have elevated serum creatinine. These differences may be due to glomerular hyperfiltration and proximal tubular damage as a secondary factor to chronic anemia and iron overload. These observations are in concordance with other studies that showed increased creatinine clearance and GFR in patients with $\beta$-thalassemia major. Moreover, anemia reduces systemic vascular resistance resulting in a hyperdynamic circulation. This, in turn, increases renal plasma flow and GFR [25]. We did not find a significant correlation between serum hepcidin and serum ferritin in this study. The literature has confirmed this finding as well [26-28].

Based on both bivariate correlation and multivariate regression, with adjustment for the socio-demographic aspects, we demonstrated that there is a statistically significant negative linear correlation between serum hepcidin and serum creatinine, and eGFR. These results are consistent with those obtained in other studies [29-31] which have shown that there is an inverse correlation between serum hepcidin levels and eGFR. Therefore, to find out the real correlation between serum hepcidin and eGFR, we came up with a novel index, named HeGRI, and it could be used as an index of the appropriateness of serum hepcidin suppression associated with the degree of tubular dysfunction and glomerular hyperfiltration; normally HeGRI should be close to zero.

In the present study, we found that the median HeGRI of the pediatric and adult cases $(0.12$ and 0.12$)$ was significantly higher $(p<0.023$ and $p<0.001)$ than their matched controls (0.08 and 0.06$)$, with a median case-control difference of -0.04 and -0.06 , respectively. It means that hepcidin is not decreased proportionately to the degree of renal dysfunction despite the higher level of eGFR in $\beta$-thalassemia major patients. We hypothesize that higher eGFR levels could be a secondary reason, after ineffective erythropoiesis, for serum hepcidin suppression in $\beta$-thalassemia major patients.

Furthermore, the logic behind the negative correlation between serum hepcidin and creatinine came backs to the role of creatinine in determining renal function and GFR [32].

\section{Strengths and Limitations}

To our knowledge, this is the first age- and gender-matched $\beta$-thalassemia major study that compared serum hepcidin with renal function and eGFR. In addition, the study examined its correlation with indicators of anemia, iron status, and inflammation. Monitoring renal function using only serum creatinine and eGFR may not be sufficient. Hence, other markers of renal and tubular dysfunction such as serum cystatin- $C$, urine $\mathrm{N}$-acetyl-b-D-glucosaminidase excretion, and serum and urinary $\beta 2$-microglobulin are suggested to be examined in future studies.

The higher level of serum hepcidin in $\beta$-thalassemia major patients may mask our hypothesis; therefore, we recommend a pre-post cohort study to examine the serum hepcidin status before and after transfusion and also to check the urine hepcidin level in study groups and correlate them with renal function tests and eGFR in the future studies. 


\section{Conclusions}

As conclusion, there was a statistically significant negative linear correlation between serum hepcidin and total iron-binding capacity, transferrin saturation, serum creatinine and eGFR.

Our results revealed that progressive renal insufficiency results in an altered hepcidin metabolism, which subsequently affects enteric iron absorption and the availability of iron stores. Furthermore, glomerular hyperfiltration and proximal tubular damage secondary to ineffective erythropoiesis in $\beta$-thalassemia major patients may cause a lowering of serum hepcidin levels; accordingly, we suggest HeGRI as a novel index of the appropriateness of serum hepcidin suppression associated with the degree of tubular dysfunction and glomerular hyperfiltration in $\beta$-thalassemia major patients.

Author Contributions: Conceptualization, B.A.Z. and S.O.R.; methodology, B.A.Z. and N.M.R.I.; validation, B.A.Z., S.O.R. and D.M.A.; formal analysis, D.M.A.; investigation, B.A.Z.; resources, B.A.Z.; data curation, B.A.Z. and D.M.A.; writing-original draft preparation, B.A.Z., S.O.R., N.M.R.I. and D.M.A.; writing-review and editing, B.A.Z., S.O.R., D.M.A. and N.M.R.I.; visualization, B.A.Z. and D.M.A.; supervision, B.A.Z. and S.O.R.; project administration, B.A.Z.; funding acquisition, all authors. All authors have read and agreed to the published version of the manuscript.

Funding: This research received no external funding.

Institutional Review Board Statement: The study was conducted according to the guidelines of the Declaration of Helsinki, and approved by the Institutional Review Board (or Ethics Committee) of Directorate General of Health (protocol code 10092019-6 and 10 September 2019).

Informed Consent Statement: Informed consent was obtained from all subjects involved in the study.

Data Availability Statement: The data that support the findings of this study are available from the corresponding author, B.A.Z., upon reasonable request.

Acknowledgments: The authors of the study would like to present their deep thanks to Duhok Thalassemia Center, Zheen Center for Cancer and Blood Diseases, for their kind cooperation and assistance.

Conflicts of Interest: The authors declare no conflict of interest.

\section{References}

1. Hoffbrand, A.; Moss, P.; Pettit, I. Hypochromic anaemias. Esential Haematology, 6th ed.; Wiley-Blackwell: Chichester, UK, 2011; pp. 34-49.

2. Chauhan, R.; Sharma, S.; Chandra, J. What regulates hepcidin in poly-transfused $\beta$-Thalassemia Major: Erythroid drive or store drive? Indian J. Pathol. Microbiol. 2014, 57, 39. [CrossRef] [PubMed]

3. Berdoukas, V.; Nord, A.; Carson, S.; Puliyel, M.; Hofstra, T.; Wood, J.; Coates, T.D. Tissue iron evaluation in chronically transfused children shows significant levels of iron loading at a very young age. Am. J. Hematol. 2013, 88, E283-E285. [CrossRef]

4. Zaman, B.; Rasool, S.; Jasim, S.; Abdulah, D. Hepcidin as a diagnostic biomarker of iron deficiency anemia during pregnancy. J. Matern.-Fetal Neonatal Med. 2019, 34, 1288-1296. [CrossRef] [PubMed]

5. Van Santen, S.; Kroot, J.J.; Zijderveld, G.; Wiegerinck, E.T.; Spaanderman, M.E.; Swinkels, D.W. The iron regulatory hormone hepcidin is decreased in pregnancy: A prospective longitudinal study. Clin. Chem. Lab. Med. 2013, 51, 1395-1401. [CrossRef] [PubMed]

6. Wray, K.; Allen, A.; Evans, E.; Fisher, C.; Premawardhena, A.; Perera, L.; Rodrigo, R.; Goonathilaka, G.; Ramees, L.; Webster, C. Hepcidin detects iron deficiency in $\mathrm{S}$ ri $\mathrm{L}$ ankan adolescents with a high burden of hemoglobinopathy: A diagnostic test accuracy study. Am. J. Hematol. 2017, 92, 196-203. [CrossRef]

7. Kato, A.; Tsuji, T.; Luo, J.; Sakao, Y.; Yasuda, H.; Hishida, A. Association of prohepcidin and hepcidin-25 with erythropoietin response and ferritin in hemodialysis patients. Am. J. Nephrol. 2008, 28, 115-121. [CrossRef] [PubMed]

8. Roe, M.A.; Spinks, C.; Heath, A.L.; Harvey, L.J.; Foxall, R.; Wimperis, J.; Wolf, C.; Fairweather-Tait, S.J. Serum prohepcidin concentration: No association with iron absorption in healthy men; and no relationship with iron status in men carrying HFE mutations, hereditary haemochromatosis patients undergoing phlebotomy treatment, or pregnant women. Br. J. Nutr. 2007, 97, 544-549. [CrossRef]

9. Kemna, E.H.; Kartikasari, A.E.; van Tits, L.J.; Pickkers, P.; Tjalsma, H.; Swinkels, D.W. Regulation of hepcidin: Insights from biochemical analyses on human serum samples. Blood Cells Mol. Dis. 2008, 40, 339-346. [CrossRef] [PubMed] 
10. Zaritsky, J.; Young, B.; Wang, H.-J.; Westerman, M.; Olbina, G.; Nemeth, E.; Ganz, T.; Rivera, S.; Nissenson, A.R.; Salusky, I.B. Hepcidin-A potential novel biomarker for iron status in chronic kidney disease. Clin. J. Am. Soc. Nephrol. 2009, 4, $1051-1056$. [CrossRef]

11. Swinkels, D.W.; Girelli, D.; Laarakkers, C.; Kroot, J.; Campostrini, N.; Kemna, E.H.; Tjalsma, H. Advances in quantitative hepcidin measurements by time-of-flight mass spectrometry. PLOS ONE 2008, 3, e2706. [CrossRef]

12. Schwartz, G.; Haycock, G.; Edelmann, C.; Spitzer, A. A simple estimate of glomerular filtration rate in children derived from body length and plasma creatinine. Pediatrics 1976, 58, 259-263. [CrossRef]

13. Levey, A.S.; Stevens, L.A.; Schmid, C.H.; Zhang, Y.L.; Castro, A.F.; Feldman, H.I.; Kusek, J.W.; Eggers, P.; Van Lente, F.; Greene, T. A new equation to estimate glomerular filtration rate. Ann. Intern. Med. 2009, 150, 604-612. [CrossRef] [PubMed]

14. Burtis, C.A.; Ashwood, E.R.; Bruns, D.E. Tietz Textbook of Clinical Chemistry and Molecular Diagnostics-e-Book; Elsevier Health Sciences: Amsterdam, The Netherlands, 2012.

15. Nemeth, E. Hepcidin in $\beta$-thalassemia. Ann. New York Acad. Sci. 2010, 1202, 31. [CrossRef] [PubMed]

16. Kearney, S.L.; Nemeth, E.; Neufeld, E.J.; Thapa, D.; Ganz, T.; Weinstein, D.A.; Cunningham, M.J. Urinary hepcidin in congenital chronic anemias. Pediatric Blood Cancer 2007, 48, 57-63. [CrossRef]

17. Gardenghi, S.; Ramos, P.; Marongiu, M.F.; Melchiori, L.; Breda, L.; Guy, E.; Muirhead, K.; Rao, N.; Roy, C.N.; Andrews, N.C. Hepcidin as a therapeutic tool to limit iron overload and improve anemia in $\beta$-thalassemic mice. J. Clin. Investig. 2010, 120, 4466-4477. [CrossRef] [PubMed]

18. Nemeth, E. Hepcidin and $\beta$-thalassemia major. Blood 2013, 122, 3-4. [CrossRef] [PubMed]

19. Jagadishkumar, K.; Yerraguntla, N.; Vaddambal, M. Serum Hepcidin Levels in Children with Beta Thalassemia Major. Indian Pediatrics 2018, 55, 911-912. [CrossRef] [PubMed]

20. Kaddah, A.M.; Abdel-Salam, A.; Farhan, M.S.; Ragab, R. Serum hepcidin as a diagnostic marker of severe iron overload in beta-thalassemia major. Indian J. Pediatrics 2017, 84, 745-750. [CrossRef] [PubMed]

21. Rashidy, F.H.; Elghar, H.M.A.; Eldin, S.M.K.; Taha, M.Z. Hepcidin and iron regulation in chronic hemolytic anemia. Menoufia Med. J. 2015, 28, 463.

22. Paköz, Z.B.; Çekiç, C.; Arabul, M.; Sarıtaş Yüksel, E.; İpek, S.; Vatansever, S.; Ünsal, B. An evaluation of the correlation between hepcidin serum levels and disease activity in inflammatory bowel disease. Gastroenterol. Res. Pract. 2015, 2015, 810942. [CrossRef] [PubMed]

23. Papanikolaou, G.; Tzilianos, M.; Christakis, J.I.; Bogdanos, D.; Tsimirika, K.; MacFarlane, J.; Goldberg, Y.P.; Sakellaropoulos, N.; Ganz, T.; Nemeth, E. Hepcidin in iron overload disorders. Blood 2005, 105, 4103-4105. [CrossRef]

24. Origa, R.; Galanello, R.; Ganz, T.; Giagu, N.; Maccioni, L.; Faa, G.; Nemeth, E. Liver iron concentrations and urinary hepcidin in $\beta$-thalassemia. Haematologica 2007, 92, 583-588. [CrossRef] [PubMed]

25. Musallam, K.M.; Taher, A.T. Mechanisms of renal disease in $\beta$-thalassemia. J. Am. Soc. Nephrol. 2012, 23, 1299-1302. [CrossRef] [PubMed]

26. Tantiworawit, A.; Khemakapasiddhi, S.; Rattanathammethee, T.; Hantrakool, S.; Chai-Adisaksopha, C.; Rattarittamrong, E.; Norasetthada, L.; Charoenkwan, P.; Srichairatanakool, S.; Fanhchaksai, K. Correlation of hepcidin and serum ferritin levels in thalassemia patients at Chiang Mai University Hospital. Biosci. Rep. 2021, 41, BSR20203352. [CrossRef] [PubMed]

27. Haghpanah, S.; Esmaeilzadeh, M.; Honar, N.; Hassani, F.; Dehbozorgian, J.; Rezaei, N.; Abdollahi, M.; Bardestani, M.; Safaei, S.; Karimi, M. Relationship between serum hepcidin and ferritin levels in patients with thalassemia major and intermedia in Southern Iran. Iran. Red Crescent Med. J. 2015, 17, e28343. [CrossRef]

28. Ashby, D.R.; Gale, D.P.; Busbridge, M.; Murphy, K.G.; Duncan, N.D.; Cairns, T.D.; Taube, D.H.; Bloom, S.R.; Tam, F.W.; Chapman, R.S. Plasma hepcidin levels are elevated but responsive to erythropoietin therapy in renal disease. Kidney Int. 2009, 75, 976-981. [CrossRef] [PubMed]

29. Malyszko, J.; Malyszko, J.; Pawlak, K.; Mysliwiec, M. Hepcidin, an acute-phase protein and a marker of inflammation in kidney transplant recipients with and without coronary artery disease. Transplant. Proc. 2006, 38, 2895-2898. [CrossRef] [PubMed]

30. Malyszko, J.; Malyszko, J.S.; Pawlak, K.; Mysliwiec, M. Hepcidin, iron status, and renal function in chronic renal failure, kidney transplantation, and hemodialysis. Am. J. Hematol. 2006, 81, 832-837. [CrossRef] [PubMed]

31. Longerfich, L. Predicting glomerular function from adjusted serum creatinine. Nephron 1992, 62, $249-256$.

32. Levey, A.S.; Bosch, J.P.; Lewis, J.B.; Greene, T.; Rogers, N.; Roth, D. A more accurate method to estimate glomerular filtration rate from serum creatinine: A new prediction equation. Ann. Intern. Med. 1999, 130, 461-470. [CrossRef] 